\title{
Factors associated with in-hospital mortality in infants undergoing heart transplantation in the United States
}

\author{
Rupali Gandhi, MD, JD, ${ }^{\mathrm{a}}$ Christopher Almond, MD, MPH, ${ }^{\mathrm{a}, \mathrm{b}}$ Tajinder P. Singh, MD, MSc, ${ }^{\mathrm{a}, \mathrm{b}}$ \\ Kimberlee Gauvreau, $\mathrm{ScD},{ }^{\mathrm{a}, \mathrm{c}}$ Gary Piercey, $\mathrm{BS},{ }^{\mathrm{a}}$ and Ravi R. Thiagarajan, MBBS, $\mathrm{MPH}^{\mathrm{a}}{ }^{\mathrm{b}}$
}

Objective: Infants undergoing heart transplantation have the highest early posttransplant mortality of any age group. We sought to determine the pretransplantation factors associated with in-hospital mortality in transplanted infants in the current era.

Methods: All infants under 12 months of age who underwent primary heart transplantation during a recent 10-year period (1999-2009) in the United States were identified using the Organ Procurement and Transplant Network database. Multivariable logistic regression was used to identify independent pretransplantation factors associated with in-hospital mortality.

Results: Of 730 infants in the study (median age 3.8 months), $462(63 \%)$ had congenital heart disease, 282 $(39 \%)$ were supported by a ventilator, $94(13 \%)$ with extracorporeal membrane oxygenation, and $22(3 \%)$ with a ventricular assist device at the time of transplantation. Overall, $82(11.2 \%)$ infants died before their initial hospital discharge. In adjusted analysis, in-hospital mortality was associated with repaired congenital heart disease (odds ratio [OR], 3.6; 95\% confidence interval [CI], 1.8, 7.2), unrepaired congenital heart disease not on prostaglandin $\mathrm{E}(\mathrm{OR}, 2.8$; CI, 1.3, 6.1), extracorporeal membrane oxygenator support (OR, 6.1; CI, 2.8, 13.4), ventilator support $(\mathrm{OR}, 4.4 ; \mathrm{CI}, 2.3,8.3)$, creatinine clearance less than $40 \mathrm{~mL} \cdot \mathrm{min}^{-1} \cdot 1.73 \mathrm{~m}^{-2}(\mathrm{OR}, 3.1$; CI, $1.7,5.3)$, and dialysis ( $\mathrm{OR}, 6.2 ; \mathrm{CI}, 2.1,18.3)$ at transplantation.

Conclusions: One in 9 infants undergoing heart transplantation dies before hospital discharge. Pretranplantation factors associated with early mortality include congenital heart disease, extracorporeal membrane oxygenator support, mechanical ventilation, and renal failure. Risk stratification for early posttransplant mortality among infants listed for heart transplantation may improve decision-making for transplant eligibility, organ allocation, and posttransplant interventions to reduce mortality. (J Thorac Cardiovasc Surg 2011;141:531-6)

\section{Supplemental material is available online.}

Infants undergoing heart transplantation (HT) face the highest early mortality of all children undergoing HT. ${ }^{1,2}$ However, those who survive the early period have the best long-term survival. ${ }^{2,3}$ Because infants account for approximately one

\footnotetext{
Department of Cardiology, ${ }^{\mathrm{a}}$ Children's Hospital Boston; Department of Pediatrics, ${ }^{\mathrm{b}}$ Harvard Medical School; and Department of Biostatistics, ${ }^{\mathrm{c}}$ Harvard School of Public Health, Boston, Mass.

This study was supported by Alexia Clinton Family Fund, Department of Cardiology, Children's Hospital Boston. The work was supported in part by Health Resources and Services Administration contract 234-2005-370011C.

Disclosures: The data reported here were supplied by the United Network for Organ Sharing as the contractor for the Organ Procurement and Transplantation Network (OPTN). The interpretation and reporting of these data are the responsibility of the authors and in no way should be seen as an official policy of or interpretation by the OPTN or the US Government.

Received for publication July 9, 2010; revisions received Sept 14, 2010; accepted for publication Oct 15, 2010

Address for reprints: Rupali Gandhi, MD, JD, Department of Cardiology, 300 Longwood Ave, Boston, MA 02115 (E-mail: Rupali.Gandhi@childrens.harvard.edu). 0022-5223/ $\$ 36.00$

Copyright (C) 2011 by The American Association for Thoracic Surgery doi:10.1016/j.jtcvs.2010.10.025
}

fourth of pediatric heart transplants performed in the United States, reduction in early posttransplant mortality in this group not only will improve long-term survival in infants undergoing HT but also will benefit overall pediatric HT survival.

Although age has been evaluated as a risk factor for early posttransplant mortality within the broad context of pediatric $\mathrm{HT}$, few studies have focused on the infant population alone. Infants undergoing HT are unique by virtue of the prevalence of congenital heart disease (CHD) compared with older children, their internal heterogeneity with respect to prostaglandin-dependent circulation, and their exposure to cardiac surgery. ${ }^{3,4}$ In addition, infants' size constraints result in a relative scarcity of donor organs and long waiting times before HT, which may increase the risk of end-organ dysfunction from prolonged exposure to insufficient organ perfusion and complications from medications used to support cardiac function. ${ }^{5}$ Moreover, most previous studies have analyzed mortality at arbitrary intervals after HT, which may have been useful to assess center performance ${ }^{1,3,4,6}$ but may not be optimal for designing strategies to improve early posttransplant outcomes. Inhospital mortality as an end point is important, not only because hospital discharge after HT is a clinical milestone, but 


$$
\begin{aligned}
& \text { Abbreviations and Acronyms } \\
& \begin{aligned}
\text { CHD } & =\text { congenital heart disease } \\
\text { ECMO } & =\text { extracorporeal membrane oxygenation } \\
\text { HT } & =\text { heart transplantation } \\
\text { IQR } & =\text { interquartile range } \\
\text { OPTN } & =\text { Organ Procurement and } \\
& \text { Transplantation Network } \\
\text { US } & =\text { United States } \\
\text { VAD } & =\text { ventricular assist device }
\end{aligned}
\end{aligned}
$$

also because an improved understanding of factors driving early mortality in this high-risk group may influence decisions about criteria and timing for listing and for emerging mechanical support devices.

The purpose of this study, therefore, was to identify the pretransplant factors associated with in-hospital mortality among infants undergoing HT in the current era.

\section{METHODS \\ Study Population}

All patients less than 12 months of age who underwent their first orthotopic HT in the United States (US) between January 20, 1999, and January 20, 2009, were identified in the Organ Procurement and Transplantation Network (OPTN) database. The OPTN is an internally audited, mandatory, solid-organ transplant registry that includes data on all solid-organ transplants in the US as submitted by the members of the network. The US Department of Health and Human Services provides oversight of the activities of the OPTN contractor, the United Network for Organ Sharing. We excluded infants who underwent multivisceral transplantation. All children were followed up from the time of HT until death or hospital discharge.

\section{Study Definitions and Outcome Measures}

The primary outcome measure was in-hospital mortality, defined as infants who received heart transplants and died before their initial hospital discharge. All clinical and demographic variables were defined at the time of HT. Pretransplant mechanical cardiorespiratory support was categorized as extracorporeal membrane oxygenation (ECMO) support, ventilator support (without ECMO), or no support (neither ECMO nor ventilator support). Creatinine clearance was calculated using the formula presented by Schwartz and associates. ${ }^{7}$ We also assessed the primary cause of death in infants who died.

\section{Statistical Analysis}

Summary statistics are presented as median (interquartile range [IQR]) or number (percent). Patient characteristics were compared among diagnostic subgroups using the $\chi^{2}$ test for categorical variables and the Kruskal-Wallis test for continuous variables. Characteristics of patients who died versus those who survived were compared by the Wilcoxon rank sum test or $\chi^{2}$ test, as appropriate. Hospital mortality rates are displayed with $95 \%$ exact binomial confidence intervals. A multivariable logistic regression model was used to identify independent factors associated with in-hospital mortality. Only risk factors that were statistically significant at the .05 level were retained in the final model. Analyses were performed using statistical software SAS version 9.1 (SAS Institute Inc, Cary, NC) and STATA version 10.0 (StataCorp LP, College Station, Tex). All authors had full access to the data and take responsibility for its integrity.

\section{RESULTS \\ Study Cohort}

A total of 730 infants underwent orthotopic HT in the US during the study period. The baseline characteristics of these infants are summarized in Table 1 and Figure E1. The primary cardiac diagnosis was CHD in $462(63 \%)$, cardiomyopathy in $224(30 \%)$, and other in $44(6 \%)$ patients. The median age of the cohort was 3.8 months (IQR, 1.7-6.6 months) and the median weight was $4.7 \mathrm{~kg}$ (IQR, 3.6-6.0 kg). The median donor weight was $7.0 \mathrm{~kg}$ (IQR, $5.0-10.0 \mathrm{~kg}$ ), and the donor/recipient weight ratio was 1.5 (IQR, 1.1-1.9). Overall, infants receiving heart transplants due to CHD were younger $(P<.001)$ and smaller $(P<.001$ for weight and body surface area) than infants listed for cardiomyopathy. Ninety-four (13\%) infants were supported by ECMO at the time of transplant, 213 $(29 \%)$ were supported with mechanical ventilation without ECMO, $22(3 \%)$ were supported with a ventricular assist device (VAD), $120(16 \%)$ were receiving prostaglandin E (PGE), and 20 (3\%) were supported with dialysis. Of the 113 patients with repaired CHD who were supported with PGE, 20 carried the diagnosis of hypoplastic left heart syndrome. Infants with CHD were more likely to have a creatinine clearance less than $40 \mathrm{~mL} \cdot \mathrm{min}^{-1} \cdot 1.73 \mathrm{~m}^{-2}$ $(P=.10)$, and infants with cardiomyopathy were more likely to be using a VAD at the time of transplant $(P<.001)$.

\section{In-Hospital Mortality}

Eighty-two (11.2\%) of 730 infants died before their hospital discharge. Table 2 summarizes univariate variables of early hospital mortality before discharge. Infants who died were younger and smaller than survivors. Other factors associated with in-hospital mortality included ECMO or ventilator support at HT, prior sternotomy, creatinine clearance less than $40 \mathrm{~mL} \cdot \min ^{-1} \cdot 1.73 \mathrm{~m}^{-2}$, dialysis at the time of HT, and a bloodstream infection within 2 weeks preceding HT. VAD and PGE use were not associated with higher inhospital mortality and only 1 patient supported with a VAD died; however, the total number of patients using a VAD $(\mathrm{n}=22)$ was small.

Figure 1 summarizes unadjusted in-hospital mortality for infants receiving heart transplants according to diagnosis (Figure 1, A), level of invasive support (Figure 1,B), and renal function (Figure 1,C). Infants with repaired CHD were far more likely to die before hospital discharge than were the infants with cardiomyopathy $(21 \%$ vs $5 \% ; P<.001)$. A substantial increase in mortality was seen on the basis of the level of invasive support, with patients supported by ECMO having the highest mortality. Finally, infants with renal failure, estimated by creatinine clearance less than $40 \mathrm{~mL} \cdot \min ^{-1} \cdot 1.73 \mathrm{~m}^{-2}$, had a significantly worse outcome than did those with creatinine clearance of $40 \mathrm{~mL} \cdot \min ^{-1} \cdot 1.73 \mathrm{~m}^{-2}$ or more. 
TABLE 1. Baseline characteristics of the infant cohort by cardiac diagnosis*

\begin{tabular}{|c|c|c|c|c|c|c|c|}
\hline & \multirow[b]{2}{*}{$\begin{array}{c}\text { Total } \\
(n=730)\end{array}$} & \multicolumn{3}{|c|}{ Congenital heart disease } & \multirow[b]{2}{*}{$\begin{array}{c}\text { CMP } \\
(n=224)\end{array}$} & \multirow[b]{2}{*}{$\begin{array}{c}\text { Other } \\
(n=44)\end{array}$} & \multirow[b]{2}{*}{$P$ value } \\
\hline & & $\begin{array}{l}\text { Repaired } \\
(n=194) \\
\end{array}$ & $\begin{array}{l}\text { Unrepaired, on } \\
\text { PGE }(n=113)\end{array}$ & $\begin{array}{l}\text { Unrepaired, no } \\
\text { PGE }(n=155)\end{array}$ & & & \\
\hline Recipient age (mo) & $3.8(1.7-6.6)$ & $4.7(1.7-7.4)$ & $1.5(0.7-2.7)$ & $2.8(1.3-4.6)$ & $5.9(3.7-8.4)$ & $5.0(2.3-7.7)$ & $<.001$ \\
\hline Recipient weight $(\mathrm{kg})$ & $4.7(3.6-6.0)$ & $4.9(3.6-6.2)$ & $3.6(3.2-4.3)$ & $4.1(3.4-5.0)$ & $5.6(4.7-6.8)$ & $5.0(4.1-6.2)$ & $<.001$ \\
\hline Donor weight (kg) & $7.0(5.0-10.0)$ & $7.0(5.3-10.0)$ & $6.0(4.0-8.0)$ & $6.0(4.4-8.6)$ & $7.7(6.0-11.0)$ & $7.0(5.8-10.0)$ & $<.001$ \\
\hline $\begin{array}{c}\text { Donor/recipient } \\
\text { weight ratio }\end{array}$ & $1.5(1.1-1.9)$ & $1.5(1.2-1.9)$ & $1.6(1.1-2.0)$ & $1.5(1.1-2.0)$ & $1.4(1.1-1.8)$ & $1.5(1.1-2.0)$ & .30 \\
\hline Recipient BSA (kg/m²) & $0.27(0.23-0.32)$ & $0.28(0.23-0.33)$ & $0.23(0.21-0.26)$ & $0.24(0.21-0.28)$ & $0.31(0.27-0.35)$ & $0.28(0.25-0.33)$ & $<.001$ \\
\hline Donor BSA & $0.35(0.28-0.44)$ & $0.36(0.29-0.45)$ & $0.31(0.24-0.38)$ & $0.32(0.25-0.41)$ & $0.38(0.31-0.49)$ & $0.35(0.31-0.48)$ & $<.001$ \\
\hline $\begin{array}{l}\text { Donor/recipient } \\
\text { BSA ratio }\end{array}$ & $1.3(1.08-1.57)$ & $1.30(1.11-1.56)$ & $1.35(1.07-1.66)$ & $1.35(1.07-1.59)$ & $1.26(1.07-1.51)$ & $1.26(1.1-1.6)$ & .41 \\
\hline Female sex & $331(45 \%)$ & $71(37 \%)$ & $40(35 \%)$ & $67(43 \%)$ & $132(59 \%)$ & $21(48 \%)$ & $<.001$ \\
\hline Nonwhite race & $265(36 \%)$ & $62(32 \%)$ & $41(36 \%)$ & $54(35 \%)$ & $93(42 \%)$ & $15(34 \%)$ & .35 \\
\hline Blood type $\mathrm{O}$ & $326(45 \%)$ & $82(42 \%)$ & $51(45 \%)$ & $69(45 \%)$ & $102(46 \%)$ & $22(50 \%)$ & .90 \\
\hline PRA $>10 \%$ & $42(14 \%)$ & $16(22 \%)$ & $7(14 \%)$ & $6(9 \%)$ & $11(12 \%)$ & $2(13 \%)$ & .28 \\
\hline ABO-incompatible & $54(7 \%)$ & $21(11 \%)$ & $8(7 \%)$ & $12(8 \%)$ & $9(4 \%)$ & $4(9 \%)$ & .10 \\
\hline ECMO & $94(13 \%)$ & $51(26 \%)$ & $2(2 \%)$ & $8(5 \%)$ & $27(12 \%)$ & $6(14 \%)$ & $<.001$ \\
\hline Ventilator & $213(29 \%)$ & $63(32 \%)$ & $31(27 \%)$ & $40(26 \%)$ & $66(29 \%)$ & $13(30 \%)$ & $<.001$ \\
\hline $\begin{array}{l}\text { Neither ECMO } \\
\text { nor ventilator }\end{array}$ & $423(58 \%)$ & $80(41 \%)$ & $80(71 \%)$ & $107(69 \%)$ & $131(58 \%)$ & $25(57 \%)$ & $<.001$ \\
\hline VAD & $22(3 \%)$ & $0(0 \%)$ & $1(1 \%)$ & $2(1 \%)$ & $16(7 \%)$ & $3(7 \%)$ & $<.001$ \\
\hline PGE & $120(16 \%)$ & $5(3 \%)$ & $113(100 \%)$ & $0(0 \%)$ & $1(<1 \%)$ & $1(2 \%)$ & $<.001$ \\
\hline Dialysis & $20(3 \%)$ & $13(7 \%)$ & $1(1 \%)$ & $1(1 \%)$ & $3(1 \%)$ & $2(5 \%)$ & .002 \\
\hline $\begin{array}{l}\text { Creatinine clearance } \\
\quad<40 \mathrm{~mL} \cdot \mathrm{min}^{-1} \\
1.73 \mathrm{~m}^{-2}\end{array}$ & $141(20 \%)$ & $41(22 \%)$ & $28(25 \%)$ & $35(24 \%)$ & $31(15 \%)$ & $6(14 \%)$ & .10 \\
\hline $\begin{array}{l}\text { BSI within } 2 \text { wk before } \\
\text { transplant }\end{array}$ & $212(31 \%)$ & $74(40 \%)$ & $31(28 \%)$ & $33(22 \%)$ & $63(30 \%)$ & $11(28 \%)$ & .01 \\
\hline Prior sternotomy & $101(32 \%)$ & $86(100 \%)$ & $0(0 \%)$ & $0(0 \%)$ & $7(7 \%)$ & $8(47 \%)$ & $<.001$ \\
\hline
\end{tabular}

$P G E$, Prostaglandin E; $C M P$, cardiomyopathy; $B S A$, body surface area; $P R A$, panel of reactive antibodies; $E C M O$, extracorporeal membrane oxygenation; $V A D$, ventricular assist device; BSI, bloodstream infection. *All clinical variables defined at the time of heart transplantation. Total number of patients varies for each row due to incomplete data entry.

The multivariable factors associated with in-hospital mortality are presented in Table 3. Repaired CHD, unrepaired CHD without PGE, ECMO support at HT, ventilator support at HT, and renal failure (including creatinine clearance $<40 \mathrm{~mL} \cdot \min ^{-1} \cdot 1.73 \mathrm{~m}^{-2}$ or dialysis at $\mathrm{HT}$ ) were independently associated with in-hospital mortality. There was a significant increase in mortality if the primary diagnosis was repaired CHD or unrepaired CHD without PGE. Unrepaired CHD with PGE and VAD support at HT were not significantly associated with in-hospital mortality in the multivariable model.

Figure 2 depicts the observed hospital mortality rate for infants undergoing HT in the presence of more than 1 risk factor. The observed in-hospital mortality rate ranged from as low as 3\% (infants with cardiomyopathy not requiring invasive hemodynamic support or dialysis) to as high as $78 \%$ (infants supported by ECMO and requiring dialysis). Listing status was not independently associated with posttransplant outcome, perhaps because the vast majority of infants are listed status 1A at the time of transplant (Figure E2).

The primary causes of death for infants who underwent HT but failed to survive to hospital discharge are shown in Table E1. Non-rejection-related graft failure and endorgan failure together accounted for nearly $60 \%$ of the early infant deaths. Rejection-related graft failure accounted for less than $10 \%$ of early deaths. In univariate analysis, ECMO support was the only factor significantly associated with death after hospital discharge (Table E2).

\section{DISCUSSION}

In this study we found that, in the current era, $11.2 \%$ of infants undergoing HT fail to survive to hospital discharge, a mortality rate that is approximately $50 \%$ higher than that of older children receiving heart transplants. However, the mortality rate is not constant across all infants but varies by more than 20 -fold ( $3 \%$ vs $78 \%$ ) based on patientspecific factors. Infants with repaired CHD or unrepaired CHD not receiving PGE, those supported with ECMO or mechanical ventilation, and those with renal failure at the time of HT experienced increased mortality.

Several studies have analyzed factors associated with early mortality in children undergoing HT. ${ }^{1,3,4,6,8-10}$ However, analyses focusing on infants have been limited to singlecenter experiences ${ }^{4}$ or multicenter experiences from the 
TABLE 2. Univariate variables of in-hospital mortality after infant heart transplantation*

\begin{tabular}{|c|c|c|c|}
\hline & $\begin{array}{l}\text { Survived } \\
(\mathrm{n}=648)\end{array}$ & $\begin{array}{c}\text { Died } \\
(\mathrm{n}=\mathbf{8 2})\end{array}$ & $P$ value \\
\hline Age (mo) & $3.9(1.8-6.8)$ & $2.5(1.1-5.3)$ & .004 \\
\hline Weight (kg) & $5.0(3.6-6.0)$ & $4.0(3.2-5.1)$ & $<.001$ \\
\hline Donor weight (kg) & $7.0(5.0-10.0)$ & $6.0(4.0-8.0)$ & .003 \\
\hline $\begin{array}{c}\text { Donor/recipient } \\
\text { weight ratio }\end{array}$ & $1.5(1.1-1.9)$ & $1.4(1.1-1.9)$ & .7 \\
\hline BSA & $0.28(0.23-0.32)$ & $0.24(0.21-0.3)$ & .001 \\
\hline $\begin{array}{l}\text { Donor/recipient } \\
\text { BSA ratio }\end{array}$ & $1.31(1.08-1.57)$ & $1.26(1.04-1.57)$ & .66 \\
\hline Ischemic time & $3.8(3.1-4.6)$ & $4.1(3.1-4.7)$ & .12 \\
\hline Female sex & $299(46 \%)$ & $32(39 \%)$ & .24 \\
\hline Nonwhite race & $240(37 \%)$ & $25(30 \%)$ & .27 \\
\hline Blood type & & & .42 \\
\hline Identical & $475(73 \%)$ & $55(67 \%)$ & \\
\hline Compatible & $127(20 \%)$ & $19(23 \%)$ & \\
\hline Incompatible & $46(7 \%)$ & $8(10 \%)$ & \\
\hline PRA $>10 \%$ & $40(15 \%)$ & $2(7 \%)$ & .39 \\
\hline $\begin{array}{l}\text { Cardiac diagnosis } \\
\text { CHD }\end{array}$ & & & $<.001$ \\
\hline Repaired & $153(24 \%)$ & $41(50 \%)$ & \\
\hline Unrepaired & $138(21 \%)$ & $17(21 \%)$ & \\
\hline Unrepaired on PGE & $104(16 \%)$ & $9(11 \%)$ & \\
\hline Cardiomyopathy & $212(33 \%)$ & $12(15 \%)$ & \\
\hline Other & $41(6 \%)$ & $3(4 \%)$ & \\
\hline Prior sternotomy & $82(29 \%)$ & $19(56 \%)$ & .003 \\
\hline ECMO support & $65(10 \%)$ & $29(35 \%)$ & $<.001$ \\
\hline Ventilator support & $176(27 \%)$ & $16(20 \%)$ & $<.001$ \\
\hline $\begin{array}{l}\text { Neither ECMO } \\
\text { nor ventilator }\end{array}$ & $407(63 \%)$ & $16(20 \%)$ & $<.001$ \\
\hline VAD support & $21(3 \%)$ & $1(1 \%)$ & .50 \\
\hline Dialysis support & $7(1 \%)$ & $13(16 \%)$ & $<.001$ \\
\hline $\begin{array}{l}\text { Creatinine clearance } \\
\quad<40 \mathrm{~mL} \cdot \mathrm{min}^{-1} \cdot \mathrm{m}^{-2}\end{array}$ & $106(17 \%)$ & $35(47 \%)$ & $<.001$ \\
\hline $\begin{array}{l}\mathrm{BSI} \leq 2 \text { wk before } \\
\text { transplant }\end{array}$ & $176(29 \%)$ & $36(47 \%)$ & .001 \\
\hline
\end{tabular}

$B S A$, Body surface area; PRA, panel of reactive antibodies; $C H D$, congenital heart disease; $P G E$, prostaglandin E; ECMO, extracorporeal membrane oxygenation; $V A D$, ventricular assist device; $B S I$, bloodstream infection. *All clinical variables defined at the time of heart transplantation.

$1990 \mathrm{~s},{ }^{3}$ which may not be generalizable to all centers in current times because of regional differences in practice and because of important changes in listing strategies such as ABOincompatible HT, ${ }^{11,12}$ increasing use of VAD therapy, ${ }^{13-15}$ United Network for Organ Sharing heart allocation policy revisions, ${ }^{16}$ heart donation after cardiac death, ${ }^{17}$ and advances in post-HT management. To our knowledge, this is the first multicenter analysis of early posttransplant mortality specifically in infants and in the current era.

Prior studies in HT recipients have examined early posttransplant mortality using a fixed time cutoff such as 30 days ${ }^{1,3,4,6}$ or 1 year after HT. ${ }^{1,3}$ Although both 30-day mortality and in-hospital mortality are likely to be associated with similar risk factors, in-hospital mortality that
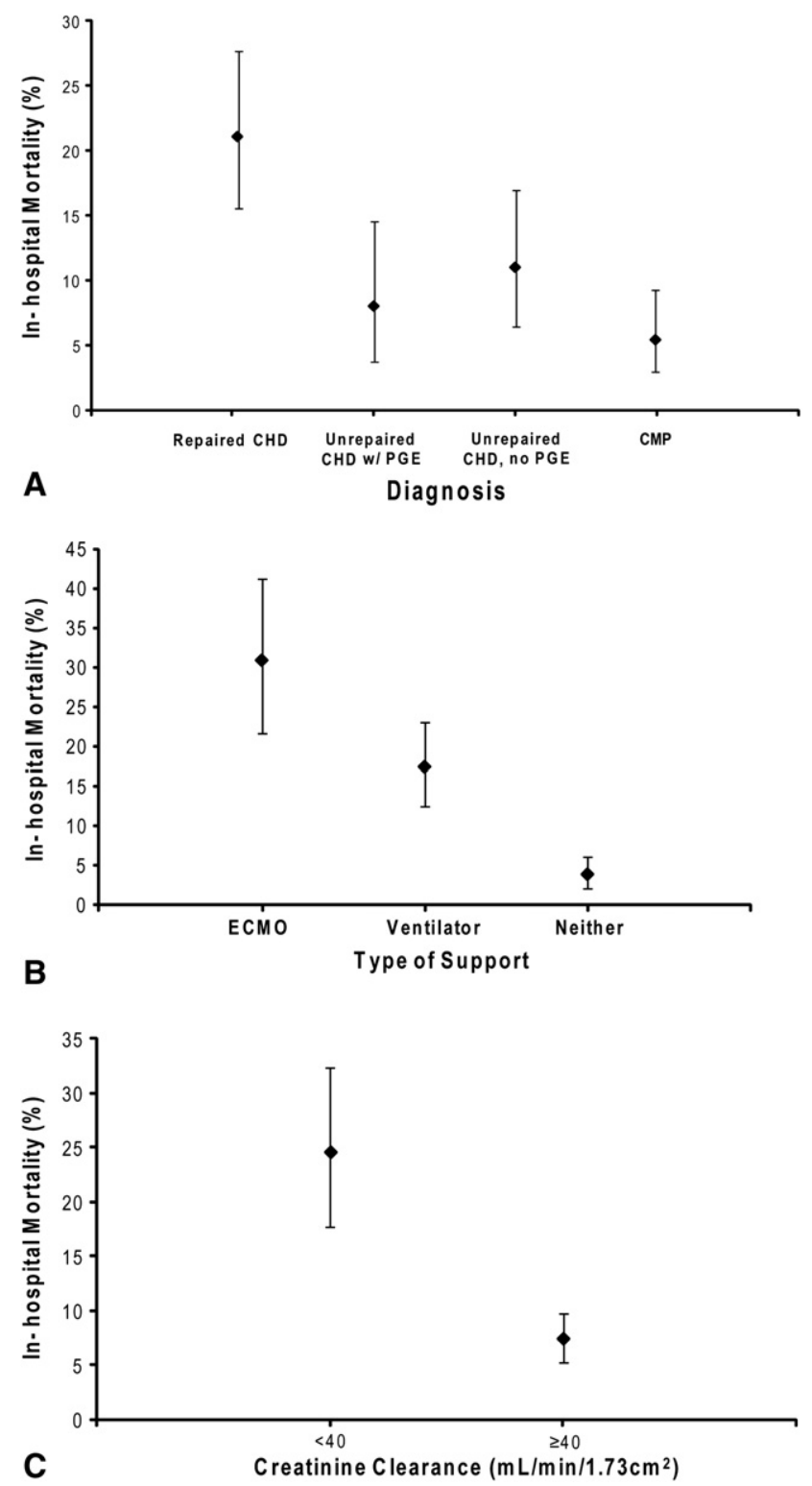

FIGURE 1. Observed rates of in-hospital mortality after heart transplantation. Infants with congenital heart disease (CHD) had a significantly higher rate of in-hospital mortality than did those with cardiomyopathy (A). Infants receiving extracorporeal membrane oxygenator (ECMO) support or ventilator support had a higher rate of in-hospital mortality than did those without such support (B). Finally, infants with a creatinine clearance less than $40 \mathrm{~mL} \cdot \min ^{-1} \cdot 1.73 \mathrm{~m}^{-2}$ had a significantly higher rate of inhospital mortality than did those with creatinine clearance greater than $40 \mathrm{~mL} \cdot \mathrm{min}^{-1} \cdot 1.73 \mathrm{~m}^{-2}(\mathrm{C}) . P G E$, Prostaglandin E.

includes deaths after 30 days is a better measure of operative mortality ${ }^{18,19}$ and is likely to be more homogeneous with respect to mechanisms compared with mortality within 30 days (or any other specified interval) that includes postdischarge deaths. Therefore, in addition to its clinical importance, in-hospital mortality provides a more accurate assessment of early mortality, and 
TABLE 3. Multivariable variables of in-hospital mortality after infant heart transplantation*

\begin{tabular}{|c|c|c|}
\hline & $\begin{array}{c}\text { Odds ratio } \\
(\mathbf{9 5} \% \text { CI })\end{array}$ & $P$ value \\
\hline \multicolumn{3}{|l|}{ Diagnostic category } \\
\hline Repaired CHD $\dagger$ & $3.6(1.8,7.2)$ & $<.001$ \\
\hline Unrepaired CHD with $\mathrm{PGE} \dagger$ & $2.0(0.8,5.1)$ & .14 \\
\hline Unrepaired CHD, no PGE $\dagger$ & $2.8(1.3,6.1)$ & .01 \\
\hline \multicolumn{3}{|l|}{ Advanced support } \\
\hline ECMO support & $6.1(2.8,13.4)$ & $<.001$ \\
\hline Ventilator & $4.4(2.3,8.3)$ & $<.001$ \\
\hline \multicolumn{3}{|l|}{ Renal function } \\
\hline $\begin{array}{l}\text { Creatinine clearance } \\
\quad<40 \mathrm{~mL} \cdot \min ^{-1} \cdot 1.73 \mathrm{~m}^{-2} \\
\quad(\mathrm{vs}>40)\end{array}$ & $3.1(1.7,5.3)$ & $<.001$ \\
\hline Creatinine value not reported & $3.9(1.5,10.3)$ & .006 \\
\hline Dialysis at transplant & $6.2(2.1,18.3)$ & .001 \\
\hline
\end{tabular}

determining which factors are associated with it may allow for interventions to reduce pretransplant risk and improve postoperative management.

We found a large heterogeneity in the observed rate of hospital mortality indicating the need for a more accurate risk stratification method using information present at the time of HT. Such a stratification method may help refine clinical decisions including defining the optimal timing for listing and for heart transplant ${ }^{20}$ de-listing because of clinical deterioration, ${ }^{20}$ timing and clinical criteria for emerging VAD technologies, ${ }^{21}$ and when transplant should be considered clinically futile and/or unethical given the scarcity of donor organs. ${ }^{22}$ For example, our findings sug-

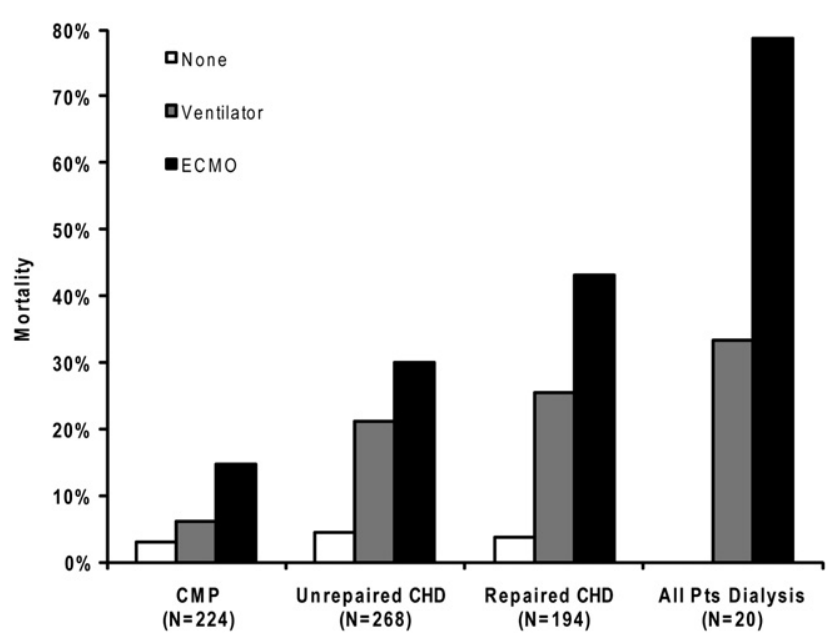

FIGURE 2. Observed in-hospital mortality for infants undergoing heart transplantation by cardiac diagnosis, level of invasive hemodynamic support, and dialysis. Dialysis group and diagnosis groups are not mutually exclusive. All infants $(\mathrm{N}=686)$. ECMO, Extracorporeal membrane oxygenation; $C M P$, cardiomyopathy; $C H D$, congenital heart disease. gest it may be reasonable for a transplant center to defer listing an infant on ECMO who requires dialysis because the posttransplant early mortality for such an infant is estimated at nearly $80 \%$ in the current era. Furthermore, these findings may be useful in establishing a clearer clinical threshold for listing, such as stable decannulation from ECMO with renal recovery, or stable transition to a VAD with recovery of renal function ${ }^{23}$ such that the risk of hospital mortality falls to more acceptable level. However, although some patient-specific factors are strongly associated with in-hospital mortality, decisions regarding proceeding to HT or advising families and clinicians regarding prognosis after HT should be based on the clinical context and the experience of the primary physician caring for the patient.

Our findings also underscore the exceedingly difficult task that policymakers face when revising the current pediatric heart allocation system. Because the most important factors associated with early posttransplant death are nearly identical to the most important factors associated with death on the waiting $\operatorname{list}^{24}$ (eg, ECMO, ventilation, poor renal function, CHD), it may be difficult for policymakers to develop an allocation scheme that prioritizes candidates who are simultaneously at a high level of medical urgency and also highly likely to benefit from transplant, as is currently done with the lung allocation scheme. ${ }^{25}$

Our analysis has several limitations. First, retrospective analyses are inherently susceptible to selection bias if a nonrandom sample population is used. However, because this analysis included all infants undergoing first-time singleorgan HT in the US, no further selection bias was imposed. Second, there were only 82 hospital deaths in the study cohort, which resulted in relatively wide confidence intervals when determining which factors were associated with higher mortality. Furthermore, detailed anatomic and surgical diagnostic data for study infants were not available, thereby limiting our ability to draw diagnosis-specific inferences among infants with CHD. Additionally, the cause of death was reported by the institutions and, therefore, potentially contains reporting bias. Finally, although the identified factors were associated with in-hospital mortality, the effect of these factors on long-term mortality cannot be assumed.

In summary, 1 in 9 infants undergoing HT does not survive to hospital discharge. The factors associated with inhospital death after transplant include cardiac diagnosis, the level of invasive support, and renal function at the time of transplant. These factors may be useful in making decisions regarding timing of transplant listing, criteria for de-listing, selection criteria for VAD support, and defining transplant futility.

\section{References}

1. Davies RR, Russo MJ, Mital S, Martens TM, Sorabella RS, Hong KN, et al. Predicting survival among high-risk pediatric cardiac transplant recipients: an analysis of the United Network for Organ Sharing database. J Thorac Cardiovasc Surg. 2008;135:147-55. 
2. Kirk R, Edwards LB, Aurora P, Taylor DO, Christie J, Dobbels F, et al. Registry of the International Society for Heart and Lung Transplantation: Eleventh Official Pediatric Heart Transplantation Report-2008. J Heart Lung Transplant. 2008;27:970-7.

3. Canter C, Naftel D, Caldwell R, Chinnock R, Pahl E, Frazier E, et al. Survival and risk factors for death after cardiac transplantation in infants. A multi-institutional study. The Pediatric Heart Transplant Study. Circulation. 1997;96:227-31.

4. Zuppan CW, Wells LM, Kerstetter JC, Johnston JK, Bailey LL, Chinnock RE. Cause of death in pediatric and infant heart transplant recipients: review of a 20-year, single-institution cohort. J Heart Lung Transplant. 2009;28:579-84.

5. Fortuna RS, Chinnock RE, Bailey LL. Heart transplantation among 233 infants during the first six months of life: the Loma Linda experience. Loma Linda Pediatric Heart Transplant Group. Clin Transpl. 1999;263-72.

6. Azeka E, Auler JO Jr, Marcial MB, Fumagalli F, Ramires JA. Heart transplantation in children: clinical outcome during the early postoperative period. Pediatr Transplant. 2005;9:491-7.

7. Schwartz GJ, Haycock GB, Edelmann CM Jr, Spitzer A. A simple estimate of glomerular filtration rate in children derived from body length and plasma creatinine. Pediatrics. 1976;58:259-63.

8. Kirk R, Edwards LB, Aurora P, Taylor DO, Christie JD, Dobbels F, et al. Registry of the International Society for Heart and Lung Transplantation: Twelfth Official Pediatric Heart Transplantation Report-2009. J Heart Lung Transplant. 2009; 28:993-1006.

9. Simmonds J, Burch M, Dawkins H, Tsang V. Heart transplantation after congenital heart surgery: improving results and future goals. Eur J Cardiothorac Surg. 2008;34:313-7.

10. Huang J, Trinkaus K, Huddleston CB, Mendeloff EN, Spray TL, Canter CE. Risk factors for primary graft failure after pediatric cardiac transplantation: importance of recipient and donor characteristics. J Heart Lung Transplant. 2004;23:716-22.

11. Patel ND, Weiss ES, Scheel J, Cameron DE, Vricella LA. ABO-incompatible heart transplantation in infants: analysis of the United Network for Organ Sharing database. J Heart Lung Transplant. 2008;27:1085-9.

12. West LJ, Pollock-Barziv SM, Dipchand AI, Lee KJ, Cardella CJ, Benson LN, et al. ABO-incompatible heart transplantation in infants. $N$ Engl J Med. 2001; 344:793-800.

13. Rockett SR, Bryant JC, Morrow WR, Frazier EA, Fiser WP, McKamie WA, et al. Preliminary single center North American experience with the Berlin Heart pediatric EXCOR device. ASAIO J. 2008;54:479-82.
14. Stiller B, Weng Y, Hubler M, Lemmer J, Nagdyman N, Redlin M, et al. Pneumatic pulsatile ventricular assist devices in children under 1 year of age. Eur $J$ Cardiothorac Surg. 2005;28:234-9.

15. Malaisrie SC, Pelletier MP, Yun JJ, Sharma K, Timek TA, Rosenthal DN, et al. Pneumatic paracorporeal ventricular assist device in infants and children: initial Stanford experience. J Heart Lung Transplant. 2008;27:173-7.

16. Renlund DG, Taylor DO, Kfoury AG, Shaddy RS. New UNOS rules: historical background and implications for transplantation management. United Network for Organ Sharing. J Heart Lung Transplant. 1999;18:1065-70.

17. Boucek MM, Mashburn C, Dunn SM, Frizell R, Edwards L, Pietra B, et al. Pediatric heart transplantation after declaration of cardiocirculatory death. N Engl J Med. 2008;359:709-14.

18. Karamlou T, Diggs BS, Person T, Ungerleider RM, Welke KF. National practice patterns for management of adult congenital heart disease: operation by pediatric heart surgeons decreases in-hospital death. Circulation. 2008;118: 2345-52.

19. Birkmeyer JD, Siewers AE, Finlayson EV, Stukel TA, Lucas FL, Batista I, et al. Hospital volume and surgical mortality in the United States. N Engl J Med. 2002; 346:1128-37.

20. Canter CE, Shaddy RE, Bernstein D, Hsu DT, Chrisant MR, Kirklin JK, et al. Indications for heart transplantation in pediatric heart disease: a scientific statement from the American Heart Association Council on Cardiovascular Disease in the Young; the Councils on Clinical Cardiology, Cardiovascular Nursing, and Cardiovascular Surgery and Anesthesia; and the Quality of Care and Outcomes Research Interdisciplinary Working Group. Circulation. 2007;115:658-76.

21. Lietz K, Miller LW. Patient selection for left-ventricular assist devices. Curr Opin Cardiol. 2009;24:246-51.

22. Collins EG, Pfiefer PB, Mozdzierz G. Decisions not to transplant: futility or rationing. J Cardiovasc Nurs. 1995;9:23-9.

23. Sandner SE, Zimpfer D, Zrunek P, Rajek A, Schima H, Dunkler D, et al. Renal function and outcome after continuous flow left ventricular assist device implantation. Ann Thorac Surg. 2009;87:1072-8.

24. Mah D, Singh TP, Thiagarajan RR, Gauvreau K, Piercey GE, Blume ED, et al. Incidence and risk factors for mortality in infants awaiting heart transplantation in the USA. J Heart Lung Transplant. 2009;28:1292-8.

25. Egan TM, Murray S, Bustami RT, Shearon TH, McCullough KP, Edwards LB, et al. Development of the new lung allocation system in the United States. Am J Transplant. 2006;6:1212-27. 


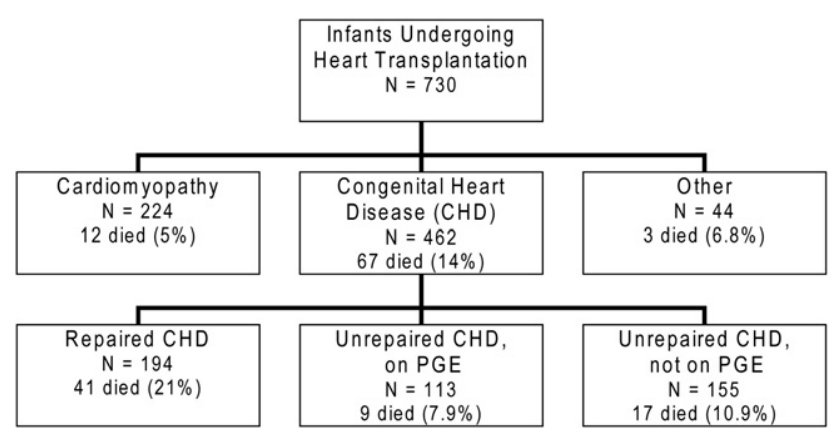

FIGURE E1. In-hospital mortality based on diagnosis at transplant. CHD, Congenital heart disease; $P G E$, prostaglandin E.
TABLE E1. Cause of death for infants undergoing heart transplantation who failed to survive to hospital discharge $(N=82)$

\begin{tabular}{lc}
\hline & $\mathbf{N}(\%)$ \\
\hline Graft failure, nonrejection & $26(31.7 \%)$ \\
End-organ failure & $23(28.0 \%)$ \\
Infection & $8(9.8 \%)$ \\
Hemorrhage & $6(7.3 \%)$ \\
Rejection & $5(6.1 \%)$ \\
Stroke & $3(3.6 \%)$ \\
Pulmonary embolism & $1(1.2 \%)$ \\
Coronary artery disease & $1(1.2 \%)$ \\
Other & $9(11 \%)$ \\
\hline
\end{tabular}

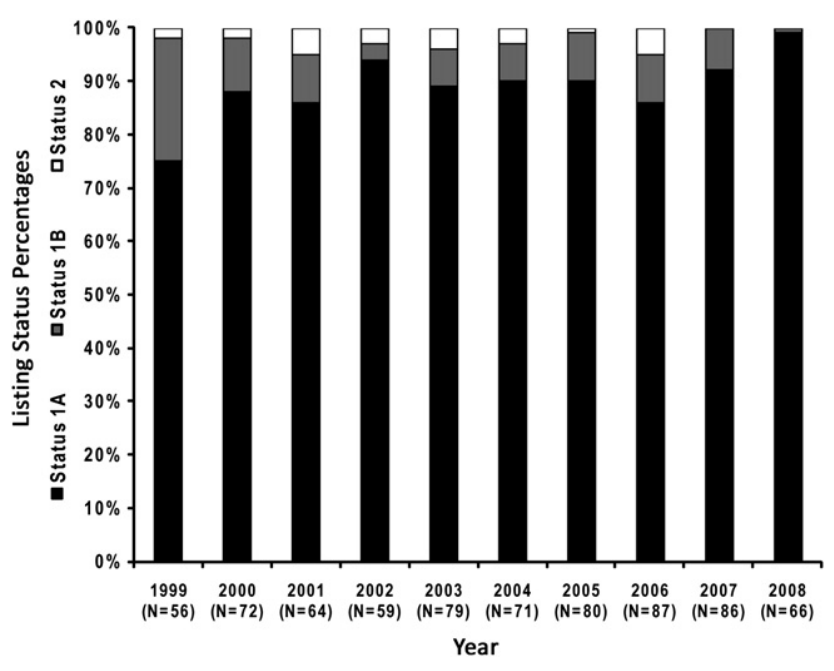

FIGURE E2. Ten-year trend in status 1A listing among US infants at time of heart transplantation. The number of infants listed status $1 \mathrm{~A}$ has increased and now almost all infants receive heart transplantation as status $1 \mathrm{~A}$.
TABLE E2. Univariate analysis of factors associated with death after hospital discharge*

\begin{tabular}{lccc}
\hline & $\begin{array}{c}\text { Hazard } \\
\text { ratio }\end{array}$ & $\mathbf{9 5 \%}$ CI & $\boldsymbol{P}$ value \\
\hline Diagnostic category & & & \\
$\quad$ Repaired CHD $\dagger$ & 0.9 & $(0.6,1.7)$ & .87 \\
$\quad$ Unrepaired CHD, with PGE $\dagger$ & 1.0 & $(0.6,1.8)$ & .97 \\
$\quad$ Unrepaired CHD, no PGE $\dagger$ & 1.4 & $(0.9,2.3)$ & .15 \\
Advanced support & & & \\
$\quad$ ECMO & 2.5 & $(1.4,4.4)$ & .001 \\
$\quad$ Ventilator & 1.3 & $(0.8,2.0)$ & .25 \\
Renal function & & & \\
$\quad$ Dialysis at time of transplant & 0.9 & $(0.1,6.1)$ & .88 \\
$\quad$ Creatinine clearance & 1.1 & $(0.7,1.9)$ & .64 \\
$\quad<40$ mL $\cdot$ min $^{-1} \cdot \mathrm{m}^{-2}$ & & & \\
$\quad$ Creatinine value not reported & 1.6 & $(0.8,3.1)$ & .20 \\
\hline
\end{tabular}

$C I$, Confidence intervals; $C H D$, congenital heart disease; $P G E$, prostaglandin E; $E C M O$, extracorporeal membrane oxygenation. *All clinical variables defined at the time of heart transplantation. $\dagger$ Reference group is structurally normal hearts (cardiomyopathy + other). 